\title{
Deactivation kinetics of V/Ti-oxide in toluene partial oxidation
}

\author{
Dmitri A. Bulushev ${ }^{a}$, Sergei I. Reshetnikov ${ }^{b}$, \\ Lioubov Kiwi-Minsker ${ }^{\mathrm{a}}$, Albert Renken ${ }^{\mathrm{a}, *}$ \\ a Swiss Federal Institute of Technology, LGRC - EPFL, CH-1015 Lausanne, Switzerland \\ ${ }^{\mathrm{b}}$ Boreskov Institute of Catalysis, 630090 Novosibirsk, Russia
}

Received 29 March 2001; received in revised form 15 May 2001; accepted 29 May 2001

\begin{abstract}
Deactivation kinetics of a V/Ti-oxide catalyst was studied in partial oxidation of toluene to benzaldehyde (BA) and benzoic acid (BAc) at 523-573 K. The catalyst consisted of 0.37 monolayer of $\mathrm{VO}_{x}$ species and after oxidative pre-treatment contained isolated monomeric and polymeric metavanadate-like vanadia species under dehydrated conditions as was shown by FT Raman spectroscopy. Under the reaction conditions via in situ DRIFTS fast formation of adsorbed carboxylate and benzoate species was observed accompanied by disappearance of the band of the monomeric species $\left(2038 \mathrm{~cm}^{-1}\right)$ (polymeric species were not controlled). Slow accumulation of maleic anhydride, coupling products and/or BAc on the surface caused deactivation of the catalyst during the reaction. Temperature-programmed oxidation (TPO) after the reaction showed formation of high amounts of $\mathrm{CO}, \mathrm{CO}_{2}$ and water. Rate constants for the steps of the toluene oxidation were derived via mathematical modelling of reaction kinetics at low conversion and constant oxygen/toluene ratio of 20:1. The model allows predicting deactivation dynamics, steady-state rates and selectivity. The highest rate constant was found for the transformation of BA into BAc explaining a low BA yield in the reaction. () 2001 Elsevier Science B.V. All rights reserved.
\end{abstract}

Keywords: V/Ti-oxide catalysts; Toluene partial oxidation; DRIFTS in situ; Kinetic modelling; Deactivation; Vanadia

\section{Introduction}

Direct selective catalytic oxidation of toluene to benzaldehyde (BA) and benzoic acid (BAc) is a reaction of industrial interest. The V/Ti-oxides are known as catalysts for this reaction [1]. However, high yields of BA and BAc have not been reached up today due to the toluene oxidation to $\mathrm{CO}_{x}$ and $\mathrm{H}_{2} \mathrm{O}$.

Steady-state kinetics of toluene oxidation over vanadia catalysts has been a subject of multiple studies [2-7], but kinetic modelling of the reaction was

\footnotetext{
* Corresponding author. Tel.: +41-21-693-31-81; fax: +41-21-693-31-90.

E-mail address: albert.renken@epfl.ch (A. Renken).
}

performed only for bulk crystalline $\mathrm{V}_{2} \mathrm{O}_{5}$ as a catalyst [7]. Supporting of vanadia on titania does not only result in advantage in higher surface area but provides the formation of new two-dimensional vanadia species which could be considered as active phase in selective oxidation of toluene [8-10].

In our earlier work [9-13], the toluene oxidation over V/Ti-oxides was studied by transient response methods and catalysts were characterised via different techniques including FT Raman spectroscopy, HRTEM, XPS, ${ }^{51} \mathrm{~V}$ MAS NMR, TPR and XRD. Deactivation of the catalyst due to carbonaceous residue formation was observed during the reaction [9], but has not been investigated in detail. The basics of deactivation kinetics in heterogeneous catalysis are considered by Froment and Bischoff [14]. 
The main objective of the present work is to study regularities of deactivation during the toluene oxidation over a well-characterised V/Ti-oxide catalyst. Spectroscopic in situ DRIFT and FT Raman techniques are applied as well as temperature-programmed oxidation (TPO) and transient response method. Conversion and selectivity to $\mathrm{BA}, \mathrm{BAc}$ and side products (maleic anhydride (MA), $\mathrm{CO}_{x}$ ) were described by a formal kinetic model.

FT-IR spectroscopy has been already applied to study toluene interaction with V/Ti-oxide and oxidation of adsorbed products [15-20], but up to our knowledge the investigation of the reaction in the presence of gaseous oxygen under dynamic conditions by spectroscopic in situ methods has not been reported yet.

\section{Experimental}

\subsection{Catalyst preparation}

Laboratory $\mathrm{TiO}_{2}$ support was prepared by hydrolysis of the tetrapropyl orthotitanate ( $>98 \%$, Fluka). XRD and Raman spectroscopy studies showed that the support possesses an anatase structure. Atomic emission spectroscopy did not indicate any potassium and sodium $(<0.01 \mathrm{wt} . \%)$. Monolayer catalyst with $1.8 \mathrm{wt} . \% \mathrm{~V}$ was prepared via well-known grafting technique $[1,21]$ by three steps of $\mathrm{VOCl}_{3}$ vapour deposition on the surface of the $\mathrm{TiO}_{2}$, followed by hydroxylation and drying. After the calcination for $120 \mathrm{~min}$ at $723 \mathrm{~K}$ the BET surface area of this catalyst was found to be $57 \mathrm{~m}^{2} / \mathrm{g}$. The amount of vanadium corresponds to 0.37 monolayer coverage of titania by $\mathrm{VO}_{x}$ species $\left(1 \mathrm{mnl}=10^{19} \mathrm{~V}\right.$ atoms $/ \mathrm{m}^{2}$ [1]). No surface impurities were found by XPS in this catalyst.

\subsection{Set-up and procedure}

Experimental set-up used for the transient kinetics study has been described elsewhere $[9,10]$. Toluene was introduced into a heated evaporator by a syringe-pump. Products were analysed by a quadrupole mass spectrometer and gas chromatograph. Measurements of conversion and selectivity were carried out in a quartz tubular reactor. A thermocouple was inserted into the middle of the catalyst layer. All lines of the set-up were heated up to $413 \mathrm{~K}$. The weight of the catalyst for the kinetic measurements was $0.061 \mathrm{~g}$, it was diluted with quartz in 1:3 ratio. The flow rates were kept at $1 \mathrm{ml}$ (STP)/s.

The catalyst was pre-treated or regenerated in oxidative atmosphere ( 20 vol. $\% \mathrm{O}_{2}$, rest Ar) at $673 \mathrm{~K}$ for $30 \mathrm{~min}$ before the reaction. DRIFTS showed that this pre-treatment allows removing of all adsorbed carbon containing species and oxidising the catalyst. After the pre-treatment, the temperature was set-up to the reaction conditions and the $\mathrm{O}_{2} / \mathrm{Ar}$ flow was switched to the mixture of 2 vol. $\%$ toluene $/ 40 \mathrm{vol} . \% \mathrm{O}_{2}$ in Ar. The temperatures of the study were in the range of $523-573 \mathrm{~K}$ to work at low conversion (differential conditions).

After 100 min of the reaction, the flow was switched back to $\mathrm{O}_{2} / \mathrm{Ar}$ and a TPO of the catalyst was performed with a heating rate of $30 \mathrm{~K} / \mathrm{min}$ to determine the amount and $\mathrm{C} / \mathrm{H}$ composition of surface carbon species. The latter was found by integration of the water and carbon oxides curves obtained during the TPO run. Relative sensitivity factors of the mass spectrometer for these products with respect to oxygen were used to determine the total amounts.

\subsection{Calculations}

Small volume change during the reaction was neglected, because of low toluene concentration and low conversions. The conversion $(X(\%))$ was determined from the toluene and product concentrations as follows:

$$
\begin{aligned}
& X=C_{\Sigma} \frac{100}{C_{\mathrm{T}, 0}}, \\
& C_{\Sigma}=C_{\mathrm{BA}}+C_{\mathrm{BAc}}+\frac{4 C_{\mathrm{MA}}}{7}+\frac{C_{\mathrm{CO}}+C_{\mathrm{CO}_{2}}}{7}
\end{aligned}
$$

where $C_{\mathrm{T}, 0}$ is the concentration of toluene at the reactor inlet, $C_{\mathrm{BA}}, C_{\mathrm{BAc}}, C_{\mathrm{MA}}, C_{\mathrm{CO}}, C_{\mathrm{CO}_{2}}$ are the concentrations of products at the reactor outlet. It is important for the comparison with the results of modelling that this equation does not take into account the toluene transformed into adsorbed products and COKE. Carbon balance was within $100 \pm 5 \%$. Coupling products, like those observed by Andersson [6] and Zhu and Andersson [7] during toluene oxidation 
on pure $\mathrm{V}_{2} \mathrm{O}_{5}$, were found only in traces. Molar selectivities $\left(S_{i}(\%)\right)$ were determined as follows:

$$
\begin{aligned}
& S_{i}=C_{i} \frac{100}{C_{\Sigma}}, \quad i=\mathrm{Ba}, \mathrm{BAc}, \mathrm{MA} \\
& S_{\mathrm{CO}_{x}}=100-S_{\mathrm{BA}}-S_{\mathrm{BAc}}-S_{\mathrm{MA}}
\end{aligned}
$$

\subsection{Spectroscopic methods}

DRIFTS and Raman in situ experiments were performed using a Perkin-Elmer FT-IR, FT Raman 2000 spectrometer. DRIFT or Raman spectroscopy cells were attached to the same set-up described above instead of the tubular reactor and the same catalyst pre-treatment was applied. The FT-IR spectrometer was equipped with a MCT detector. An amount of $0.03 \mathrm{~g}$ of the catalyst ground in an agate mortar was placed into the cup of a SpectraTech 003-102 DRIFTS cell with $\mathrm{CaF}_{2}$ windows. The time of reaching a new steady-state upon the change of the flows in the DRIFTS cell was about $10 \mathrm{~s}$. The spectra were obtained by averaging of 4-16 scans with a resolution of $4 \mathrm{~cm}^{-1}$. A single beam spectrum of the pre-oxidised catalyst was taken as a background before introduction of the toluene containing flow into the cell.

The Nd-YAG laser, operating at $1064 \mathrm{~nm}$ with a power of $430 \mathrm{~mW}$ was used in the Raman spectrometer. A Raman in situ cell is described elsewhere
[10]. Thirty-two scans were averaged with a resolution of $4 \mathrm{~cm}^{-1}$ to obtain a spectrum. The Raman spectrum of the catalyst was taken in the flow of dry 20 vol. $\% \mathrm{O}_{2} / \mathrm{Ar}$ mixture $(1 \mathrm{ml}(\mathrm{STP}) / \mathrm{s})$ at $523 \mathrm{~K}$ after the pre-treatment in this mixture at $673 \mathrm{~K}$ for $30 \mathrm{~min}$.

\section{Results and discussion}

\subsection{Structure of vanadia species and catalytic activity}

Raman spectrum of the pre-oxidised catalyst under dehydrated conditions is shown in Fig. 1. The catalyst contains two types of vanadia species: isolated monomeric species $\left(1033 \mathrm{~cm}^{-1}\right)$ and polymeric metavanadate-like species $\left(920 \mathrm{~cm}^{-1}\right)$. In both of these species pentavalent vanadium atoms are tetracoordinated [22]. No bulk crystalline $\mathrm{V}_{2} \mathrm{O}_{5}\left(994 \mathrm{~cm}^{-1}\right.$ region) is observed.

Conversion of toluene on time-on-stream is shown in Fig. 2. It is seen that the conversion decreases reaching a steady-state within $80 \mathrm{~min}$. Deactivation of V/Ti-oxide catalysts was shown to be due to carbonaceous residue accumulation on the surface [9]. Deactivation is stronger at a lower temperature (Fig. 2): at $523 \mathrm{~K}$ in the time range from 5 to $100 \mathrm{~min}$ conversion decreases 3.6 times but at $553 \mathrm{~K}$ only 2.6 times. It indicates that the concentration of species

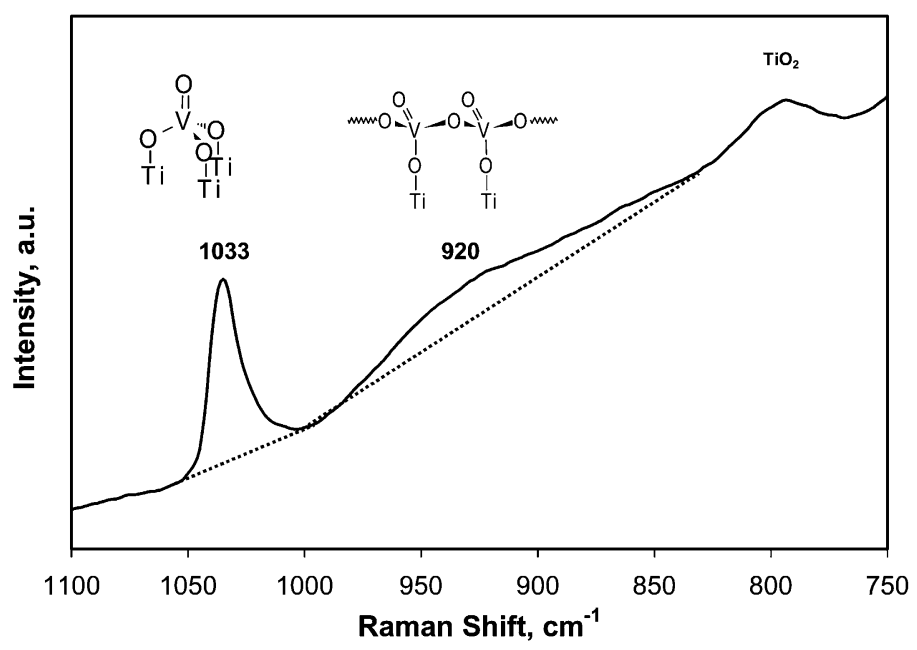

Fig. 1. FT Raman spectrum of the $1.8 \mathrm{wt} . \% \mathrm{~V} / \mathrm{TiO}_{2}$ catalyst measured in the $20 \mathrm{vol} . \% \mathrm{O}_{2} / \mathrm{Ar}$ mixture at $523 \mathrm{~K}$ under dehydrated conditions. 


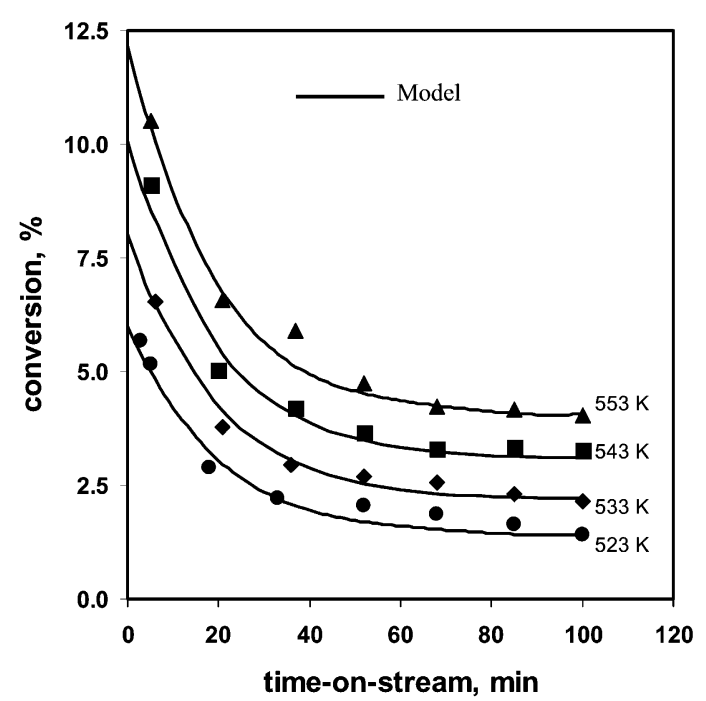

Fig. 2. Deactivation of the $1.8 \mathrm{wt} . \% \mathrm{~V} / \mathrm{TiO}_{2}$ catalyst in the 2 vol. $\%$ toluene $/ 40$ vol. $\% \mathrm{O}_{2} / 58$ vol. $\%$ Ar mixture at different temperatures (points: experiments; curves: modelling).

blocking active sites decreases with the temperature rise. This observation is in line with the data reported for the $o$-xylene oxidation over V/Ti-oxide [23].

The selectivity as a function of conversion is shown in Fig. 3a and b. The selectivity of the BA formation increases and the selectivity of the BAc formation decreases with time-on-stream due to a decrease of the toluene conversion (Fig. 2) indicating that BAc is formed via BA. MA is not found at low conversions. From [5,9], it follows its consecutive formation from BAc. The carbon oxides selectivity does not depend on conversion. It implies that they are formed via parallel route to BA, but not consecutively under the studied reaction conditions.

\subsection{In situ DRIFT spectroscopy and temperature-programmed oxidation (TPO)}

Transient response curves obtained upon a switch of the $\mathrm{O}_{2} / \mathrm{Ar}$ flow to the toluene $/ \mathrm{O}_{2} / \mathrm{Ar}$ flow were similar to the curves for the catalyst prepared by solid state reaction containing bulk crystalline $\mathrm{V}_{2} \mathrm{O}_{5}$ [9]. To determine the adsorbed species, which could be responsible for deactivation of the catalyst, DRIFT in situ spectra were obtained at different time-on-stream (Fig. 4). Switching the flow to Ar does not provide any change in the presented wavenumber region. It indicates that gaseous and reversibly adsorbed products or toluene do not contribute noticeably to the spectra. The bands at 1590,1500 , and $1440 \mathrm{~cm}^{-1}$ correspond to the phenyl $v(\mathrm{C}-\mathrm{C})$ vibrations, the bands at 1530 and $1410 \mathrm{~cm}^{-1}$ should be assigned to the asymmetric and symmetric stretching bands in carboxylate ions $\left(\mathrm{COO}^{-}\right)$. All these five bands are typical for the adsorbed benzoate [16-20].

Existence of $\mathrm{C}_{4}$ carboxylates during the toluene oxidation proposed earlier [20] does not contradict the results of the present study. Concentration of the benzoate and carboxylate species reaches a steady-state value within $52 \mathrm{~s}$. Toluene is transformed quickly into the benzoate and carboxylate-like species. Evolution of water and carbon oxides (Fig. 4, $2350 \mathrm{~cm}^{-1}, 52 \mathrm{~s}$ ) accompany these processes in accordance with the transient response data [9].

The negative band at $2038 \mathrm{~cm}^{-1}$ must be assigned to the first overtone of the $\mathrm{V}=\mathrm{O}$ stretching band, typical for the isolated monomeric vanadia species [24,25]. Fundamental $\mathrm{V}=\mathrm{O}$ stretching band is also found at $1036 \mathrm{~cm}^{-1}$ (not shown). These bands change simultaneously with the benzoate and carboxylate bands. This indicates transformation of the monomeric vanadia species into another type of vanadia species not visible by DRIFTS, which could be involved in the benzoate/carboxylate formation or strong perturbation of the monomeric species under the effect of benzoate and carboxylates.

Formation of at least two other organic species is observed in time-on-stream. The bands at 1852 and $1782 \mathrm{~cm}^{-1}$ change simultaneously and should be assigned to MA [20]. Other bands $(*)$ at 3050 (not shown), 1674, 1454, 1410, 1320, 1285 and $1180 \mathrm{~cm}^{-1}$ may correspond to coupling products like methylbenzophenone [26] and/or to moleculary adsorbed BAc [27]. A special experiment was performed to check that the formation of these products takes place on the catalyst surface but not on the windows of the cell. After 60 min of the toluene oxidation in the tubular reactor the catalyst was quickly cooled in Ar and placed into the cup of the DRIFTS cell without the $\mathrm{CaF}_{2}$ windows. The absorbance spectrum was taken with respect to the fresh catalyst. The bands with the same positions as during the in situ experiments (Fig. 4) were observed indicating that all the mentioned products are indeed present on the catalyst surface. 

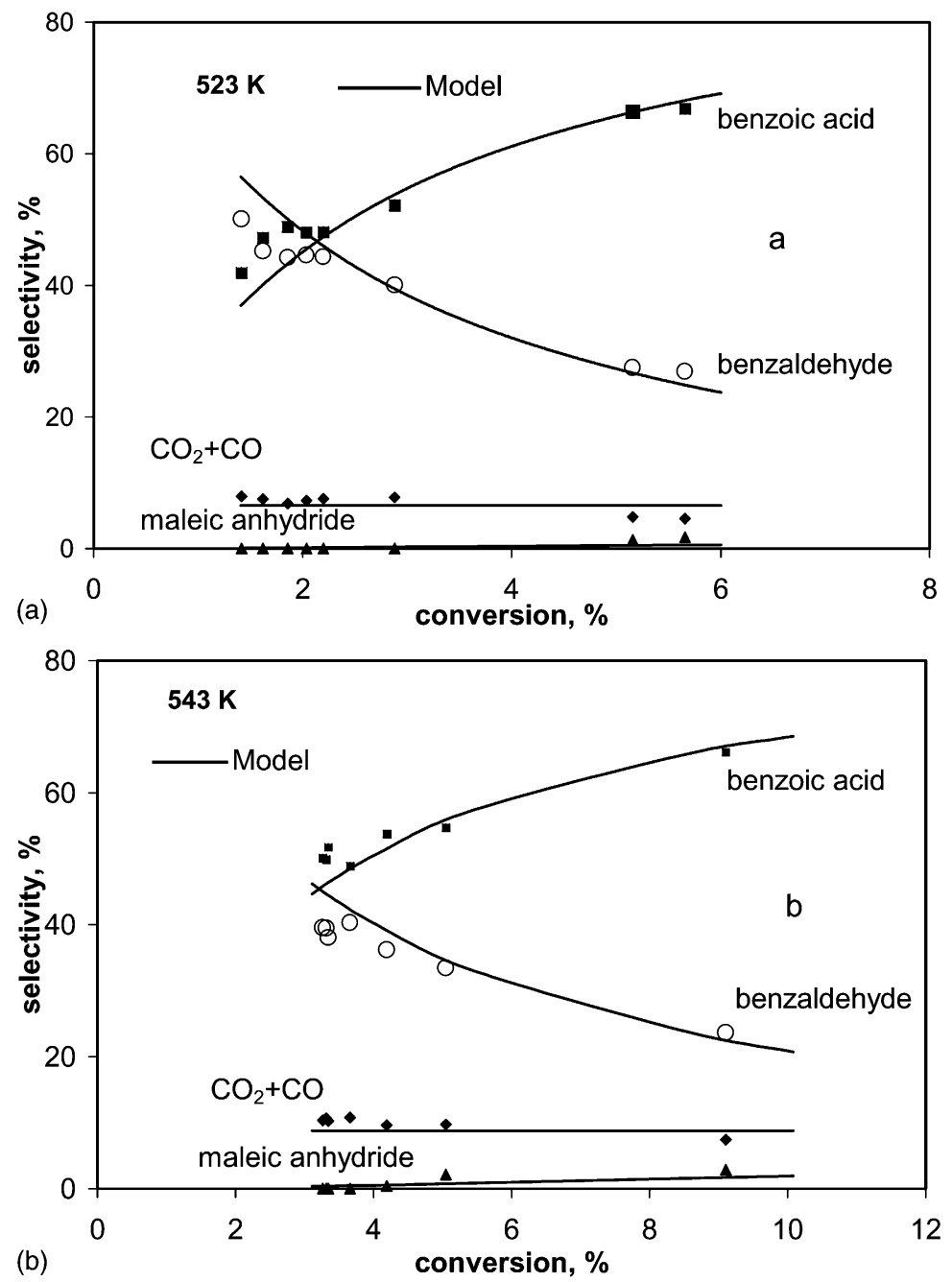

Fig. 3. Selectivity-conversion dependence for the $1.8 \mathrm{wt} . \% \mathrm{~V} / \mathrm{TiO}_{2}$ catalyst obtained in the 2 vol. $\%$ toluene/40 vol. $\% \mathrm{O}_{2} / 58 \mathrm{vol} . \%$ Ar mixture at $523 \mathrm{~K}$ (a) and $543 \mathrm{~K}$ (b) (points: experiments; curves: modelling).

Formation of coupling products during the toluene oxidation is considered in detail by Andersson and co-workers $[3,6,7]$. Strongly adsorbed residue containing up to two aromatic rings with concentration increasing in time-on-stream was found in the $o$-xylene oxidation [23]. Benzoate and carboxylate species are formed quickly. Their formation could be responsible for the initial processes taking place on the catalyst surface, but not for the slow deactivation processes in the time scale of 3-80 $\mathrm{min}$, because their concentration does not change after $52 \mathrm{~s}$ (Fig. 4). In the contrary, MA, coupling products and/or BAc are slowly accumulated on the surface and could be responsible for the deactivation.

After $100 \mathrm{~min}$ of the reaction upon a switch of the reaction mixture to the $\mathrm{O}_{2} / \mathrm{Ar}$ one, $\mathrm{BA}$ and toluene are removed relatively quickly within 10-20s (Fig. 5). The absence of a long time tailing indicates that reversible adsorption of BA as well as toluene is negligible.

Interaction of carbonaceous residue with oxygen can contribute to the $\mathrm{CO}_{2}$ formation under the reaction conditions since burning of the residue is observed after the switch to the oxygen containing mixture 


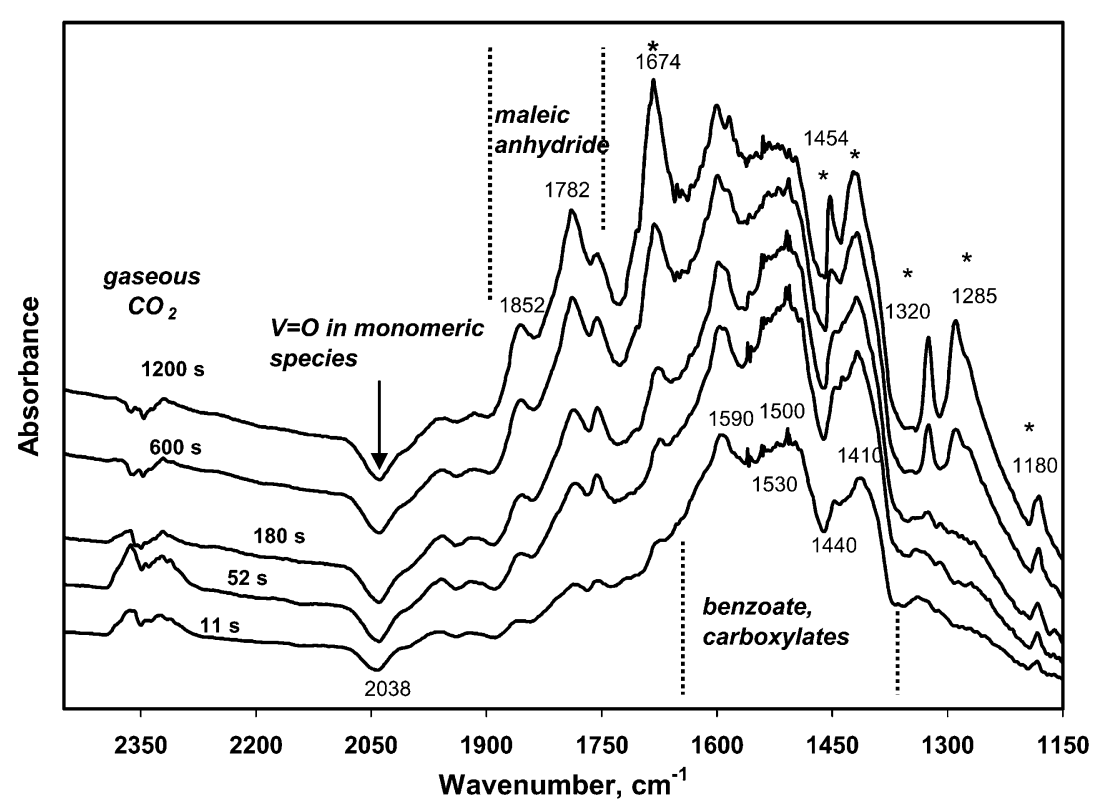

Fig. 4. DRIFT in situ spectra of the $1.8 \mathrm{wt} . \% \mathrm{~V} / \mathrm{TiO}_{2}$ catalyst in the $2 \mathrm{vol} . \%$ toluene $/ 40 \mathrm{vol} . \% \mathrm{O}_{2} / 58$ vol. $\%$ Ar mixture at $573 \mathrm{~K}$ at different time-on-stream (an asterisk $(*)$ is used to show the bands of coupling products and/or moleculary adsorbed benzoic acid).

(Fig. 5). The residue can be effectively removed in oxygen in the temperature range of $623-673 \mathrm{~K}$ in the form of $\mathrm{CO}, \mathrm{CO}_{2}$ and water, according to the TPO data (Fig. 6). The formation of BAc and MA was not observed during the TPO run. The total concentration of the carbon containing species removed from the catalyst surface corresponds to the value around $17 \mathrm{C}$ atoms $/ \mathrm{nm}^{2}$ with the $\mathrm{H} / \mathrm{C}$ atomic ratio of 0.5 . This

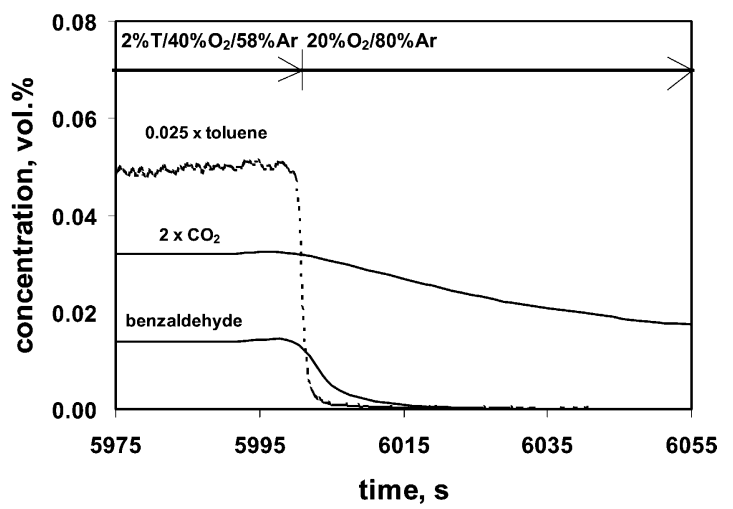

Fig. 5. Response curves obtained after the switch of the 2 vol. $\%$ toluene $/ 40$ vol. $\% \mathrm{O}_{2} / 58 \mathrm{vol} . \% \mathrm{Ar}$ mixture to the $20 \mathrm{vol} . \% \mathrm{O}_{2} / \mathrm{Ar}$ mixture over the $1.8 \mathrm{wt} . \% \mathrm{~V} / \mathrm{TiO}_{2}$ catalyst at $523 \mathrm{~K}$.

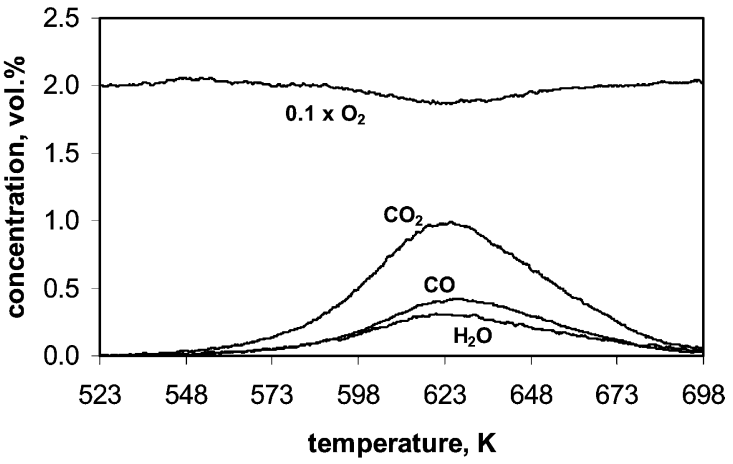

Fig. 6. Temperature-programmed oxidation (TPO) of the carbonaceous residue after $100 \mathrm{~min}$ of the reaction over $1.8 \mathrm{wt} . \% \mathrm{~V} / \mathrm{TiO}_{2}$ catalyst at $523 \mathrm{~K}$.

composition and the concentration are close to the ones for the carbonaceous residue observed by us on the catalysts prepared by solid state reaction [9].

\subsection{Kinetic modelling}

The reaction network including several consecutive/parallel reactions shown in Fig. 7 was used for kinetic modelling. BA (1), BAc (2), and MA (3) 


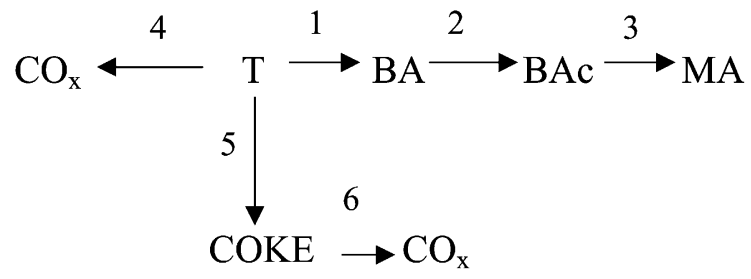

Fig. 7. Reaction network used for modelling.

are formed via a consecutive pathway in accordance with the selectivity-conversion data presented in Fig. 3 and [5,9]. Benzyl species, a possible intermediate of this pathway $[6,15,20]$ could be provided by toluene adsorption via methyl group and abstraction of one hydrogen atom from the molecule [28]. The toluene adsorption equilibrium is achieved quickly and concentration of this intermediate under the reaction conditions is negligibly small as was shown by transient response technique (Fig. 5) and DRIFTS. Hence, it could be considered as linearly dependent on the partial pressure of toluene and the step of the toluene adsorption could be neglected in the reaction network. Formation of BA takes place by addition of nucleophilic oxygen species to the benzyl species and abstraction of one more hydrogen atom [29].

The products blocking the surface are denoted as COKE (5) and imply all products responsible for a slow deactivation of the catalyst. Among them are the products of coupling formed via benzyl species [6,7]. Some of the COKE species are oxidised by gaseous oxygen to $\mathrm{CO}_{x}(6)$ under the reaction conditions as it is seen from the transient response data (Fig. 5). The contribution of this pathway to the $\mathrm{CO}_{x}$ formation should increase with the COKE concentration. Some $\mathrm{CO}_{x}$ is formed quickly in parallel to BA by the path (4) being responsible for the maximum of $\mathrm{CO}_{x}$ concentration as a function of time [9]. The maximum was also found in the $\mathrm{CO}_{2}$ behaviour in the DRIFTS with time-on-stream (Fig. 4, 52s). Toluene adsorption with aromatic ring in parallel to the surface may be responsible for this pathway via interaction with oxygen possessing electrophilic properties destroying the ring [29]. Formation of $\mathrm{CO}_{x}$ from the consecutive oxidation of MA should be taken into account, but only at higher conversions, which were not studied.

Modelling of the reaction kinetics was performed accepting quasi steady-state conditions. Concentration of active oxygen sites is taken equal to $1-\theta_{\mathrm{c}}\left(\theta_{\mathrm{c}}\right.$ is the surface fraction covered by COKE) being independent on the oxygen partial pressure under the studied conditions of excess of oxygen.

The formal kinetic steps and first-order kinetic equations are the following:

1. $\mathrm{C}_{7} \mathrm{H}_{8}+2(\mathrm{O}) \Rightarrow \mathrm{C}_{6} \mathrm{H}_{5} \mathrm{CHO}+\mathrm{H}_{2} \mathrm{O}+2()$, $r_{1}=k_{1} C_{\mathrm{T}}\left(1-\theta_{\mathrm{c}}\right)$

2. $\mathrm{C}_{6} \mathrm{H}_{5} \mathrm{CHO}+(\mathrm{O}) \Rightarrow \mathrm{C}_{6} \mathrm{H}_{5} \mathrm{COOH}+()$, $r_{2}=k_{2} C_{\mathrm{BA}}\left(1-\theta_{\mathrm{c}}\right)$

3. $\mathrm{C}_{6} \mathrm{H}_{5} \mathrm{COOH}+8(\mathrm{O}) \Rightarrow \mathrm{C}_{4} \mathrm{H}_{2} \mathrm{O}_{3}+\mathrm{CO}+2 \mathrm{CO}_{2}+$ $2 \mathrm{H}_{2} \mathrm{O}+8(), \quad r_{3}=k_{3} C_{\mathrm{BAc}}\left(1-\theta_{\mathrm{c}}\right)$

4. $\mathrm{C}_{7} \mathrm{H}_{8}+15(\mathrm{O}) \Rightarrow 3 \mathrm{CO}+4 \mathrm{CO}_{2}+4 \mathrm{H}_{2} \mathrm{O}+$ 15()$, \quad r_{4}=k_{4} C_{\mathrm{T}}\left(1-\theta_{\mathrm{c}}\right)$

5. $\mathrm{C}_{7} \mathrm{H}_{8}+(\mathrm{O}) \Rightarrow(\mathrm{COKEO}), \quad r_{5}=k_{5} C_{\mathrm{T}}\left(1-\theta_{\mathrm{c}}\right)$

6. $(\mathrm{COKEO})+7.5 \mathrm{O}_{2} \Rightarrow 3 \mathrm{CO}+4 \mathrm{CO}_{2}+4 \mathrm{H}_{2} \mathrm{O}+$ (O), $\quad r_{6}=k_{6} C_{\mathrm{O}_{2}} \theta_{\mathrm{c}}$

All the steps are supported to be irreversible in accordance with the transient response data (Fig. 5).

As the conversions were low (Fig. 2), the reactor was considered as CSTR. General equation for the CSTR was used in the form of

$\frac{\mathrm{d} C_{i}}{\mathrm{~d} t}=\frac{C_{i, 0}-C_{i}}{\tau}+R_{i}$

where $t$ is the time-on-stream, $\tau$ the space time $(0.061 \mathrm{~s})$ and $C_{i, 0}, C_{i}$ are dimensionless molar concentrations of the compounds at the reactor inlet and outlet, respectively. Transformation rates $\left(R_{i}\right)$ of a compound $i$ were taken in accordance with the reaction scheme (Fig. 7) and kinetic equations presented above. The rate of the toluene transformation is given by $R_{\mathrm{T}}=-r_{1}-r_{4}-r_{5}$, but $r_{5}$ was neglected, because the conversion of toluene into COKE was not considered in the calculations as it is mentioned above. Moreover, the modelling showed that its contribution to the total conversion is small with the maximal relative difference consisting not more than $5 \%$. To find the conversion of toluene and products selectivity at zero COKE content [14] an extrapolation to zero time was performed.

The kinetic equation for the surface coverage by COKE is as follows:

$\frac{\mathrm{d} \theta_{\mathrm{c}}}{\mathrm{d} t}=k_{5} C_{\mathrm{T}}\left(1-\theta_{\mathrm{c}}\right)-k_{6} C_{\mathrm{O}_{2}} \theta_{\mathrm{c}}$ 
Table 1

Rate constants at $523 \mathrm{~K}$ and activation energies (with $95 \%$ confidence limits) for the reaction pathways of toluene oxidation over the $1.8 \mathrm{wt} . \% \mathrm{~V} / \mathrm{Ti}$-oxide catalyst

\begin{tabular}{lllllll}
\hline & $\mathrm{T} \rightarrow \mathrm{BA}(1)$ & $\mathrm{BA} \rightarrow \mathrm{BAc}(2)$ & $\mathrm{BAc} \rightarrow \mathrm{MA}(3)$ & $\mathrm{T} \rightarrow \mathrm{CO}_{x}(4)$ & $\mathrm{T} \rightarrow \mathrm{COKE}_{(5)}$ & $\mathrm{COKE} \rightarrow \mathrm{CO}_{x}(6)$ \\
\hline$k_{i}\left(\mathrm{~s}^{-1}\right)$ & 0.972 & 47.8 & 0.135 & 0.068 & 0.0358 & 0.0005 \\
$E_{\mathrm{a}, i}(\mathrm{~kJ} / \mathrm{mol})$ & $59 \pm 5$ & $23 \pm 9$ & $128 \pm 17$ & $94 \pm 12$ & 0 & $32 \pm 4$ \\
\hline
\end{tabular}

The system of differential equations (4) and (5) was resolved by the Runge-Kutta method with the initial conditions at $t=0, \mathrm{C}_{i}=C_{i, 0}, \theta_{\mathrm{c}}=0$. Calculated conversions and selectivities were plotted against experimental ones in Figs. 2 and 3. A good correspondence is observed.

The rate constants determined at $523 \mathrm{~K}$ are presented in Table 1. The highest rate constant is found for the BA transformation into BAc. This high constant does not allow obtaining high yields of BA in the reaction. Modelling was performed at four temperatures and then activation energies for the reaction steps were estimated using Arrhenius plots (Table 1). Zero apparent activation energy for the toluene transformation into COKE is explained by the contribution of the heat of reversible adsorption of toluene, which can have the same value as the activation energy of the transformation of the adsorbed toluene into COKE.

Concentration of COKE depends on the ratio of the steps 5 and 6 . The $\theta_{\mathrm{c}}$ value can be estimated with an analytical solution of the Eq. (5) supposing $C_{\mathrm{T}}=$ $C_{\mathrm{T}, 0}$ and $C_{\mathrm{O}_{2}}=C_{\mathrm{O}_{2}, 0}$. The following relationship is obtained as follows:

$\tau_{0} \frac{\mathrm{d} \theta_{\mathrm{c}}}{\mathrm{d} t}=\theta_{\mathrm{c}, \mathrm{s}}-\theta_{\mathrm{c}}$

where $\tau_{0}=1 /\left(k_{5} C_{\mathrm{T}, 0}+k_{6} C_{\mathrm{O}_{2}, 0}\right)$ is a relaxation time of deactivation, $\theta_{\mathrm{c}, \mathrm{s}}=1 /\left(1+k_{6} C_{\mathrm{O}_{2}, 0} / k_{5} C_{\mathrm{T}, 0}\right)$ is a steady-state value of $\theta_{\mathrm{c}}$. Integrating the Eq. (6) the COKE surface concentration as a function of time-on-stream can easily be estimated as follows:

$\theta_{\mathrm{c}}=\theta_{\mathrm{c}, \mathrm{s}}\left(1-\exp \left(-\frac{t}{\tau_{0}}\right)\right)$

For the experiments shown in Fig. 2, $\theta_{\mathrm{c}, \mathrm{s}}$ were equal to 0.776 and 0.694 at 523 and $553 \mathrm{~K}$, respectively, indicating that a large part of active sites in steady-state is blocked by COKE. This correlates well with the
TPO data (Fig. 6), which give $4-5 \mathrm{C}$ atoms/V atom. It should be taken into account that the molecular structure of COKE can include more than $5 \mathrm{C}$ atoms/V site.

\section{Conclusions}

Deactivation of V/Ti-oxide catalyst has been studied in toluene oxidation by transient response method, DRIFTS in situ and kinetic modelling. Formation of benzoate/carboxylate species is a fast process. Accumulation of MA, coupling products and/or BAc on the surface is a slow process responsible for deactivation. Deactivation is found stronger at lower temperatures. A reaction network has been proposed. Formal rate constants for the routes of the toluene transformation were determined by mathematical modelling of the reaction kinetics at low conversion and constant oxygen/toluene ratio equal to $20: 1$. The model allows predicting deactivation dynamics, steady-state rates and selectivity to BA, BAc, MA and $\mathrm{CO}_{x}$.

\section{Acknowledgements}

The authors gratefully acknowledge the Swiss National Science Foundation for the financial support. The work of S.I. Reshetnikov has been supported by the Russian Foundation for Basic Research (Grant no. 01-03-32790).

\section{References}

[1] B. Grzybowska-Swierkosz, Appl. Catal. A: Gen. 157 (1997) 263.

[2] A.J. van Hengstum, J.G. van Ommen, H. Bosch, P.J. Gellings, Appl. Catal. 8 (1983) 369.

[3] B. Jonson, B. Rebenstorf, R. Larsson, S.L.T. Andersson, J. Chem. Soc., Faraday Trans. I 84 (1988) 3547. 
[4] J. Zhu, S.L.T. Andersson, J. Chem. Soc., Faraday Trans. I 85 (1989) 3629.

[5] K. Mori, A. Miyamoto, Y. Murakami, J. Chem. Soc., Faraday Trans. I 83 (1987) 3303.

[6] S.L.T. Andersson, J. Catal. 1986 (1986) 138.

[7] J. Zhu, S.L.T. Andersson, J. Catal. 126 (1990) 92.

[8] H.K. Matralis, C. Papadopoulou, C. Kordulis, A.A. Elguezabal, V.C. Corberan, Appl. Catal. A: Gen. 126 (1995) 365.

[9] D.A. Bulushev, L. Kiwi-Minsker, A. Renken, Catal. Today 57 (2000) 231.

[10] D.A. Bulushev, L. Kiwi-Minsker, V.I. Zaikovskii, A. Renken, J. Catal. 193 (2000) 145.

[11] D.A. Bulushev, L. Kiwi-Minsker, A. Renken, Catal. Today 61 (2000) 271.

[12] D.A. Bulushev, L. Kiwi-Minsker, V.I. Zaikovskii, O.B. Lapina, A.A. Ivanov, S.I. Reshetnikov, A. Renken, Appl. Catal. A: Gen. 202 (2000) 243.

[13] D.A. Bulushev, F. Rainone, L. Kiwi-Minsker, A. Renken, Langmuir 17 (2001) 5276.

[14] G.F. Froment, K.B. Bischoff, Chemical Reactor Analysis and Design, Wiley, New York, 1979 pp. 219-255.

[15] G. Busca, J. Chem. Soc., Faraday Trans. 89 (1993) 753.
[16] A.J. van Hengstum, J. Pranger, S.M. van Hengstum-Nijhuis, J.G. van Ommen, P.J. Gellings, J. Catal. 101 (1986) 323.

[17] H. Miyata, T. Mukai, T. Ono, T. Ohno, F. Hatayama, J Chem. Soc., Faraday Trans. I 84 (1988) 2465.

[18] H. Miyata, T. Ohno, F. Hatayama, J. Chem. Soc., Faraday Trans. 91 (1995) 3505.

[19] M. Sanati, A. Andersson, J. Mol. Catal. 81 (1993) 51.

[20] G. Busca, F. Cavani, F. Trifiro, J. Catal. 106 (1987) 471.

[21] G. Bond, S.F. Tahir, Appl. Catal. 71 (1991) 1.

[22] I.E. Wachs, B.M. Weckhuysen, Appl. Catal. A: Gen. 157 (1997) 67.

[23] C.R. Dias, M.F. Portela, G. Bond, J. Catal. 162 (1996) 284.

[24] U. Scharf, M. Schneider, A. Baiker, A. Wokaun, J. Catal. 149 (1994) 344.

[25] G. Ramis, G. Busca, F. Bregani, Catal. Lett. 18 (1993) 299.

[26] The Aldrich Library of FT-IR Spectra, Aldrich, 1997, p. 2647 $\mathrm{D}$.

[27] The Aldrich Library of FT-IR Spectra, Aldrich, 1997, p. 2452 $\mathrm{C}$ and D.

[28] M. Witko, K. Hermann, R. Tokarz, Catal. Today 50 (1999) 553.

[29] A. Bielanski, J. Haber, Oxygen in Catalysis, Marcel Dekker, New York, 1991, p. 414. 